\title{
The wildlife pet trade as a driver of introduction and establishment in alien birds in Taiwan
}

\author{
Shan Su • Phillip Cassey • Tim M. Blackburn
}

Received: 13 May 2015/Accepted: 11 October 2015/Published online: 27 October 2015

(C) The Author(s) 2015. This article is published with open access at Springerlink.com

\begin{abstract}
The global trade in alien cage birds is flourishing and is considered to be one of the major routes by which species are entrained into the humanmediated invasion pathway. Here, we explore the likely influence of the wild bird trade on alien bird invasions in Taiwan. Specifically, we analyse the characteristics of alien bird species that have been successfully introduced and established at large in the wild. We use phylogenetic regression models to compare the traits of alien species recorded in the
\end{abstract}

Electronic supplementary material The online version of this article (doi:10.1007/s10530-015-1003-3) contains supplementary material, which is available to authorized users.

\section{S. Su $(\square)$}

Institute of Zoology, Zoological Society of London,

Regent's Park, London NW1 4RY, UK

e-mail:su.shan@ioz.ac.uk

\section{S. Su · T. M. Blackburn}

Research Department of Genetics, Evolution and

Environment, University College London, Gower Street,

London WC1E 6BT, UK

e-mail: t.blackburn@ucl.ac.uk

P. Cassey - T. M. Blackburn

School of Biological Sciences, University of Adelaide, Adelaide, SA 5005, Australia

e-mail: phill.cassey@adelaide.edu.au

\section{T. M. Blackburn}

Department of Botany and Zoology, Centre for Invasion

Biology, Stellenbosch University, Stellenbosch,

South Africa cage bird trade in Taiwan that have (or have not) subsequently been recorded at large in the wild, and the traits of species recorded in the wild that have (or have not) established (species identified in the Breeding Bird Survey in Taiwan). Alien species were more likely to be recorded as successfully introduced if they were commonly for sale in the Taiwanese pet bird trade, and possessed songs considered to be more attractive to people. Species that have been sold in the pet market for a longer period were also more likely to have been recorded in the wild. Establishment success was more likely for large-bodied bird species, but not strongly related to other predicted determinants of success, including proxies for propagule pressure and climate matching. We conclude that the pet trade influences bird invasions in Taiwan by determining which species are exposed to novel environments there, but which of those introduced species goes on to establish may depend more on their intrinsic life histories.

Keywords Alien birds - Invasion pathway · Phylogenetic regression - Taiwan - Wildlife trade

\section{Introduction}

Geographical barriers to species distributions are being increasingly broken down by human activities, such that species are transported beyond their natural ranges to locations where they do not naturally occur 
(Davis 2009; Wilson et al. 2009; Blackburn et al. 2009a, 2011; Richardson et al. 2010). These species (here termed aliens) may subsequently establish populations in new recipient areas, and some may proceed to spread widely (i.e., invasive species) causing negative economic and environmental impacts (Kolar and Lodge 2001; Blackburn et al. 2004; Frenot et al. 2005; García-Moreno et al. 2007; Carrete and Tella 2008). These impacts have prompted an extensive body of research to understand the processes that lead species to become alien invaders.

The invasion process can usefully be studied as a sequence of stages, termed the 'invasion pathway' (Blackburn et al. 2011). In order to become 'invasive', species need to be successfully transported outside their native range, to escape or to be released from captivity or cultivation to new environments, to establish a sustainable population, and then to spread widely across the new environment. Fundamental to explaining the invasion process is an understanding of the identities and characteristics of the different species pools that lead them to complete each of these stages successfully (Kolar and Lodge 2001).

One route in which species become entrained in the invasion process is through the global wildlife trade and pet market (Westphal et al. 2008; Carrete et al. 2012). BirdLife International (2008) estimated that, in the 1990s, 2-5 million birds were involved in the global bird trade annually, while Nash (1993) estimated that 1-3 million individual songbirds were traded in Eastern countries in the same period. The number of birds acquired for bird-keeping has been estimated to be more than 2 million annually in Indonesia alone. Studies have shown that the composition of species transported in the pet market is influenced by a combination of societal demands and species availability (Blackburn et al. 2009b; Su et al. 2014). For example, birds in the pet trade in Taiwan are more likely to be widespread species, of small body mass, with attractive songs, than expected by chance (Su et al. 2014).

Species in the pet trade can become alien invaders if they are released or escape from captivity, and subsequently succeed in establishing a viable population. A key question is whether we can identify characteristics that distinguish those alien species in the pet trade, which make these transitions, from those that do not. Here, we use the cage bird market in Taiwan as a case study to test for some of these characteristics.
Taiwan has an extremely active trade in alien cage birds. More than 180,000 individuals of over 200 parrot species were imported there between 2001 and 2011, from 20 countries (Wong et al. 2012). In a survey in 1995, Severinghaus and Chi (1999) found that $6 \%$ of the more than 68,000 prayer birds recorded for sale in Taiwan were alien species, but this had risen to more than $68 \%$ of the 7634 birds recorded for sale in 2012 by Su et al. (2014). Taiwan also has a large number of alien bird species known from the wild: 90 species have been recorded at large there, of which at least 25 have been recorded breeding (see "Methods" section). More than $60 \%$ of alien bird species found in the wild are species known to have been traded in the Taiwanese pet market (Lee and Shieh 2005). We therefore predicted that the probability that an alien species is found in the wild in Taiwan is largely determined by the composition of the pet trade, and so depends on the same combination of societal demands and species availability that results in the mix of species in that trade (Su et al. 2015). We also predicted that availability determines the likelihood that an introduced species establishes a viable population, along with additional influences of the characteristics that relate to the likelihood that a species can cope with the Taiwanese environment.

Whether or not traded species get introduced into the wild depends on the likelihood that they will escape or be released. This is likely to be dependent on their abundance in shops - as commonly sold species by chance alone would be more likely to find their way into the wild - and on how much attention is provided to their care. Valuable species may be less likely to escape or be deliberately released, because more care is taken in their maintenance. Conversely, the common Taiwanese practice of prayer bird release (Shiu and Stokes 2008; Environment and Animal Society of Taiwan 2009), wherein large numbers of individuals bought from pet shops are deliberately freed, mainly concerns cheaper species (and species sold in large numbers), both native and alien (Su et al. 2015). We predicted that price will therefore be negatively correlated, and abundance in shops positively correlated, with the likelihood that an alien bird species in trade is also found in the wild. In Taiwan, the pet bird trade is also partly driven by bird singing competitions, and species with attractive songs may be more valued and better secured from escaping. We therefore also predicted that the attractiveness of bird songs to 
humans will be negatively correlated with the likelihood that a traded species is found in the wild.

Following introduction into the wild, subsequent establishment success has been shown to depend primarily on the number of individuals released, or 'propagule pressure' (Lockwood et al. 2005; Blackburn et al. 2009a, 2015). We do not have direct estimates of propagule pressure for alien birds in Taiwan, but would expect it to increase with the number of birds available for sale (and decrease with price), as more abundantly sold (and cheaper) species may escape or be deliberately released in larger numbers. Geographic range size and environmental matching have also been shown to be related to establishment success in birds (Blackburn and Duncan 2001; Duncan et al. 2006), as has body size in some studies (Cassey 2002) Therefore, we predicted that species with larger native ranges, and that originate from biogeographic realms or latitudes closer to those of Taiwan, will be more likely to establish populations. We tested for an effect of body mass on establishment success, although previous studies of this effect have been inconsistent, finding positive (Green 1997; Cassey 2002), negative (Cassey 2008), or no significant effects (Duncan et al. 2006).

Liberated alien species may take decades or longer before their populations increase and they become classified as successfully established (Runde et al. 2007). Species for sale in Taiwanese pet shops earlier, or over a longer period, may therefore be more likely to have established populations, and indeed to be recorded in the wild. Hence, we also explored whether the time period when bird species were recorded for sale in shops relates to these metrics, using data from the most comprehensive independent pet shop surveys conducted across country in three well-separated years (1994, 2004 and 2012).

\section{Methods}

Data

Our analyses of the introduction and establishment of alien birds from the Taiwanese pet trade considered two dependent variables from the invasion pathway:

1. Introduction success (or failure): whether or not an alien species recorded in a pet shop survey has been recorded in the wild. We obtained records of alien bird species in the wild in Taiwan from (Severinghaus 1999) and the Chinese Wild Bird Federation (CWBF) database for the years 1980 to 2014. These sources provided a total of 90 alien bird species recorded in the wild (Table 1). CWBF provided the most comprehensive bird records in Taiwan. However, we have found several records stated as "alien species" (with no additional details) or only available as a genus name in the dataset, and so the numbers of alien species recorded in the wild are likely to be underestimated.

2. Establishment success (or failure): whether or not a species recorded in the wild has also been recorded breeding there. While breeding records do not guarantee that an alien population is selfsustaining, species that are breeding have certainly progressed further along the invasion pathway than those have been observed in the wild but with no breeding records. Information on whether or not an alien species had been recorded breeding in the wild in Taiwan was obtained from the Severinghaus (1999), CWBF database, CWBF Checklist of Bird in Taiwan and its appendix in 2012-2014 (alien species with breeding records listed as introduced rather than established), Breeding Bird Survey Taiwan from 2009 to 2013 (Ko et al. 2013) and (Cheng 2010). To increase the likelihood that the population is actually established, we only considered a species as established if it was recorded breeding in more than one of these sources $(\mathrm{n}=25$, see Table 1$)$. We obtained data on alien species for sale in Taiwanese pet shops from three surveys: Chi (1995), Shieh et al. (2006) and Su et al. (2015). Chi (1995) surveyed 164 shops in 1994, and included information on the identity and numbers of 84 alien species for sale. Shieh et al. (2006) surveyed 146 shops in 2004, including information only on the identity of 239 alien species for sale. Su et al. (2015) surveyed 72 shops from August to November 2012, and recorded information on the identity, price, and numbers of 170 alien bird species for sale. Hereafter we refer to these as: (i) 'Chi's survey'; (ii) 'Shieh's survey'; and (iii) 'our survey'.

We classified bird species following the global taxonomic list of 9993 extant bird species from 
Table 1 The numbers of bird species recorded as introduced, and the numbers of those introduced species considered to be established, or not, in Taiwan under our criteria (Total),

\begin{tabular}{|c|c|c|c|c|}
\hline Category of species & Total & $\mathrm{Su}$ & Shieh & Chi \\
\hline Recorded for sale & & 170 & 239 & 84 \\
\hline Introduced & 90 & $40(23.5 \%)$ & $55(23.0 \%)$ & $46(54.8 \%)$ \\
\hline Not introduced & & 130 & 184 & 38 \\
\hline Established & 25 & $18(45.0 \%)$ & $20(36.4 \%)$ & $17(37.0 \%)$ \\
\hline Not established & 65 & 22 & 35 & 29 \\
\hline
\end{tabular}

Percentages are provided for the species in each survey that were successfully introduced, and for the species subsequently considered to be established

(Jetz et al. 2012). The scientific names of the species followed Birdlife Version 3 and IOC Version 2.7 taxonomies, family names followed the Birdlife guide and the order names followed Sibley and Monroe (1990), as in Jetz et al. (2012). Species were classified as alien to Taiwan based on the CWBF Checklist of the Birds of Taiwan (Ding et al. 2012), with transient migrants and vagrants not counted as native (our list of Taiwanese native species is available upon request).

We collected information on the following predictor variables for each of the species recorded across all three pet shop surveys:

1. Geographical range size $\left(\mathrm{km}^{2}\right)$ : a measurement of native geographic range extent (Gaston 1991, 1994), acquired from the data collated by Orme et al. (2006). Areas of total native breeding range for all species were converted to polygons on equal area grids with a cell size of $96.3 \mathrm{~km} \times 96.3 \mathrm{~km}$. This specified a scale identical to $1^{\circ}$ grids at the equator. The native breeding area of each species was estimated by summing the areas of the cells in which they occurred (Orme et al. 2006; Blackburn and Cassey 2007). These values were natural $\log$ transformed for analysis.

2. Biogeographic realms: species were assigned to realms as defined using the World Wildlife Fund eco-regions map (Olson et al. 2001), on the basis of the region in which the largest part of their native range fell.

3. Latitude of origin (degrees): we defined this as the latitudinal mid-point of the native geographic range, calculated as the median latitude of the central point of the grid cell where species occurs. together with the number of these species also recorded for sale in Taiwanese pet shops in this paper, Shieh's and Chi's survey 
their body masses were available for 169 of the 170 species recorded for sale in our survey. Data on the price of alien species displayed for sale was available for 167 species. Therefore the introduction analysis was conducted on 167 species.

Analysis

All analyses were conducted in $\mathrm{R}$ version 3.0.3 ( $\mathrm{R}$ Core Team 2014), using the caper (Orme et al. 2013) and phylolm (Ho and Ane 2014) packages.

We tested for phylogenetic correlation among species in terms of whether or not they were introduced, and whether or not they were established. These are both binary variables, and so we calculated the phylogenetic threshold model D statistic, (function phylo.d in the $\mathrm{R}$ package caper), a measure of phylogenetic signal strength in binary traits proposed by Fritz and Purvis (2010). D = 1 when the sum of sister-clade differences in a binary trait is phylogenetically randomly distributed throughout the tips of the phylogeny, whereas $D=0$ if the trait evolved under a Brownian threshold model. Although introduction and establishment success are not evolved traits, they may be correlated with species traits that are (Cassey 2002), and the threshold model for calculating character dispersion on a phylogeny provides a way to scale phylogenetic signal strength under a specified evolutionary hypothesis (Fritz and Purvis 2010). The phylogenetic tree for birds is not known for certain (Jetz et al. 2012), and so we incorporated uncertainty about the true phylogenetic relationship by repeating our analyses on 100 different phylogenetic trees for our species, sampled at random from birdtree.org, and calculating the median, 1st and 99th percentiles value of $\mathrm{D}$ over all trees.

For the species recorded for sale in Taiwan by our survey, we tested for differences in the characteristics of species that have been recorded as introduced $(\mathrm{n}=40)$ versus those that have not $(\mathrm{n}=130)$. Likewise, for species recorded for sale in Taiwan by Chi's survey, we compared characteristics of the species recorded as introduced $(\mathrm{n}=46)$ versus those not $(\mathrm{n}=38$; Table 1). Shieh et al. (2006) included information only on the identity of alien species for sale, and not on their numbers (a key predictor under our hypotheses), and so we did not test for differences in introduction success for the species in Shieh's survey.
We generated models of whether or not a traded species in our survey was introduced in terms of the variables we had predicted to affect it: price, numbers of bird for sale, song attractiveness, and body mass. We used the phyloglm function in the $R$ package phylolm (Ho and Ane 2014) to test each of the predictor variables separately, and to fit all possible multivariate models from these predictor variables, using a phylogenetic logistic regression approach (Phylogenetic Generalized Linear Model) (Ives and Garland 2010). We again repeated our analyses on 100 different phylogenetic trees to incorporate uncertainty about the true phylogenetic relationship. For each phylogenetic tree, we identified the best model based on Akaike's Information Criterion adjusted for small sample size (AICc), and the set of most likely models (those with $\triangle \mathrm{AICc}<4$ ). We used these models to calculate the Akaike weight for each model and the variable importance for each predictor variable. Our study has a relatively small sample size for analyses of establishment success; this is because species are filtered out by the sequential stages of the process of invasion, and so the numbers of alien species in the later stages are (almost) always less than at earlier stages.

We used the same analytical methods to test for determinants of whether or not a traded species in Chi's survey was introduced into the wild. We used the numbers of birds for sale, song attractiveness and body mass as predictor variables.

The predictor variables for the determinants of establishment success were price, numbers of birds for sale, latitudinal mid-point of the range, body mass and native breeding range size. Latitudinal range midpoint is a significant predictor of biogeographic realm of origin in our data (adjusted $\mathrm{r}^{2}=0.49$, $\mathrm{F}(4,161)=40.3, p<0.001)$, and so we used only the former, continuous variable (including a quadratic term), in our analyses. We tested for difference in the characteristics of introduced species considered to be established $(\mathrm{n}=18)$ versus those introduced but considered not to be established $(\mathrm{n}=22)$. We again performed our analysis using data from Chi's survey, in which, 17 introduced species were considered to be established, and 29 not (Table 1).

We used the R package VennDiagram (Chen and Boutros 2011) to visualise the overlap between the numbers of introduced species across surveys, and the R package beanplot (Kampstra 2008) for box plots. 


\section{Results}

The three pet shop surveys, together with the sources of data for introduced and established species, included a total of 341 alien bird species recorded in Taiwan, of which 312 species were recorded for sale in pet shops (Appendix in Electronic supplementary material). Of the 90 alien species recorded as introduced in Taiwan, 29 (32.3\%) were recorded in all three surveys (Fig. 1), versus 15 of the $251(6 \%)$ alien bird species not recorded as introduced; there is a strong relationship between whether or not species were traded and their wild record status $\left(\chi^{2}=38.3\right.$, df $=1, p<0.001)$. A high percentage of both introduced and established species were those that had been recorded for sale: almost $70 \%$ of the introduced species (62/90) and more than $90 \%(23 / 25)$ of established species occurred in at least one of the three pet shop surveys (Table 1). The percentage of bird species in a survey that were introduced differs across surveys $\left(\chi^{2}=33.9\right.$, df $\left.=2, p<0.001\right)$, with Chi's survey having the highest percentage of traded species that were also found in the wild, but the percentage of introduced alien bird species that have established does not $\left(\chi^{2}=0.8, \mathrm{df}=2, p=0.65\right)$.

Whether or not the alien species recorded in our survey were introduced into the wild showed an intermediate level of phylogenetic correlation (median

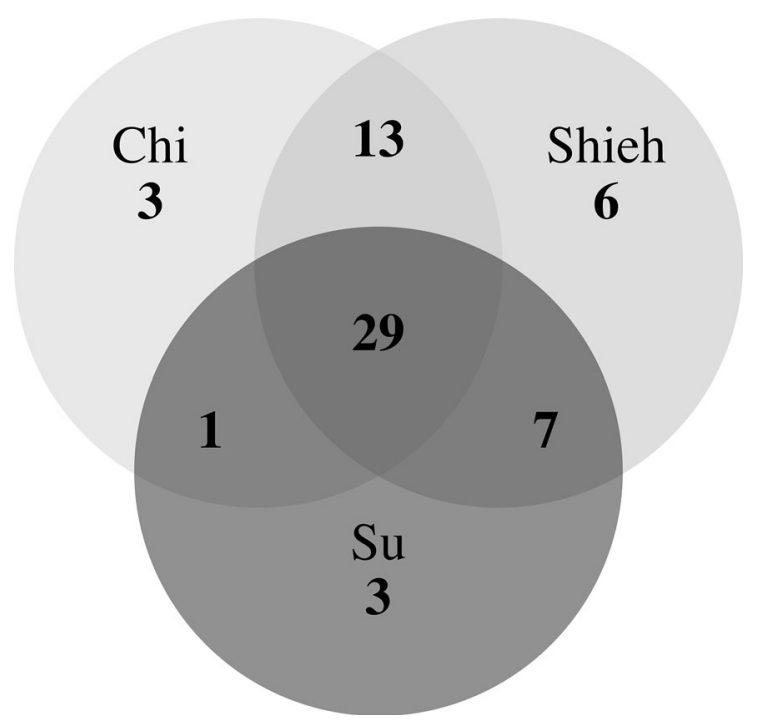

Fig. 1 The numbers of the introduced species overlap across ours $(\mathrm{Su}, \mathrm{n}=40$ ), Chi's (Chi $\mathrm{n}=46$ ) and Shieh's (Shieh $\mathrm{n}=55$ ) surveys
$\mathrm{D}$ value $=0.46 .1$ st and 99th percentiles over 100 likely phylogenetic trees: $0.39,0.52$ ), and the same is true for the alien species recorded for sale in Chi's survey $(\mathrm{D}=0.47,1$ st and 99th percentiles: 0.42 , 0.51). Likewise, establishment success showed an intermediate level of phylogenetic correlation across the species recorded in our survey $(\mathrm{D}=0.38,1$ st and 99th percentiles: $0.32,0.44$ ) and in Chi's survey ( $\mathrm{D}=0.55,1$ st and 99th percentiles: $0.50,0.59$ ).

Univariate analysis revealed that introduction success for bird species recorded for sale in our survey was related to the numbers of birds for sale, their price and song attractiveness (Fig. 2). The most likely model (of three models with $\triangle \mathrm{AICc}<4$ ) was composed of just two factors: positive effects of both the numbers of birds for sale and song attractiveness (Table 2). These two variables were also present in all the most likely models (median variable importance $=0.99$, 1st and 99th percentiles: 0.99, 0.99). Both of the other two predictor variables (price and body mass) were included in the other two most likely models as negative effects, albeit with lower variable importance (Table 2). The three most likely models accounted for $>94 \%$ of the Akaike weight across all models.

Univariate analysis revealed that introduction success for bird species recorded for sale in Chi's survey was related to the numbers of birds for sale only (Fig. 3). The best model (of four models with $\triangle \mathrm{AICc}$ $<4$; which accounted for $92 \%$ of the Akaike weight) also included the numbers of birds for sale, which had a median variable importance value of 0.93 (1st and 99th percentiles: 0.88, 0.96; Table 3). Song attractiveness and body mass did not have strong effects on introduction success for the birds recorded in Chi's survey.

For establishment success, univariate analysis found that none of the tested variables had a strong effect on whether or not an introduced alien species recorded from our pet shop survey was established in Taiwan, although there was a moderate negative effect of price (Table 4a). Phylogenetic logistic regression analysis identified seven models with $\Delta \mathrm{AICc}<4$, but only body mass was a consistent predictor of establishment success (Table 5); body mass was present in all the most likely models, with a median importance value of 0.98 (1st and 99th percentiles: 0.96, 0.99).

None of the tested variables showed a strong effect on whether or not the introduced alien species 
(a) Estimate: $-0.4(-0.64,-0.26)$; P: $0.001(<0.001,0.01)$

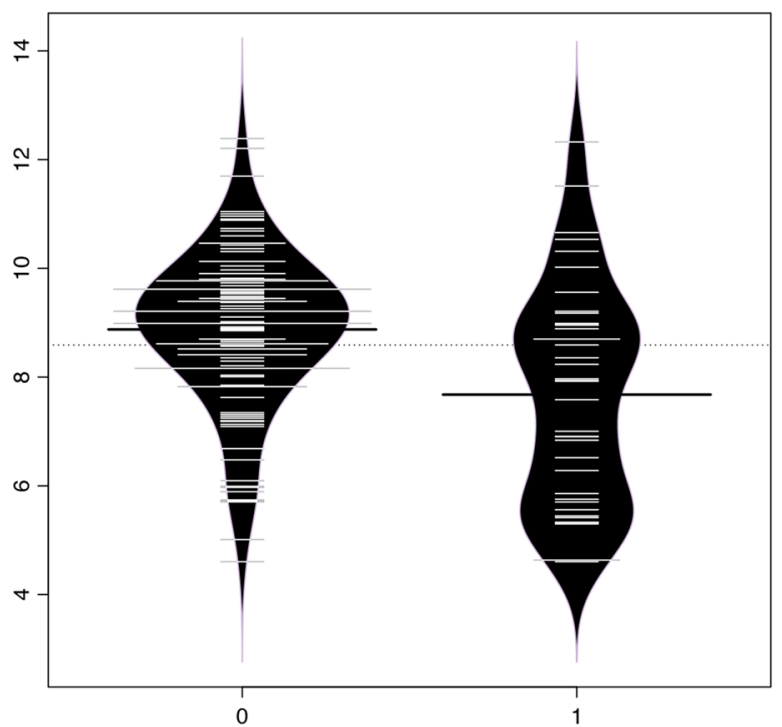

(c) Estimate: $0.72(0.68,0.77) ; p: 0.001(0.001,0.002)$

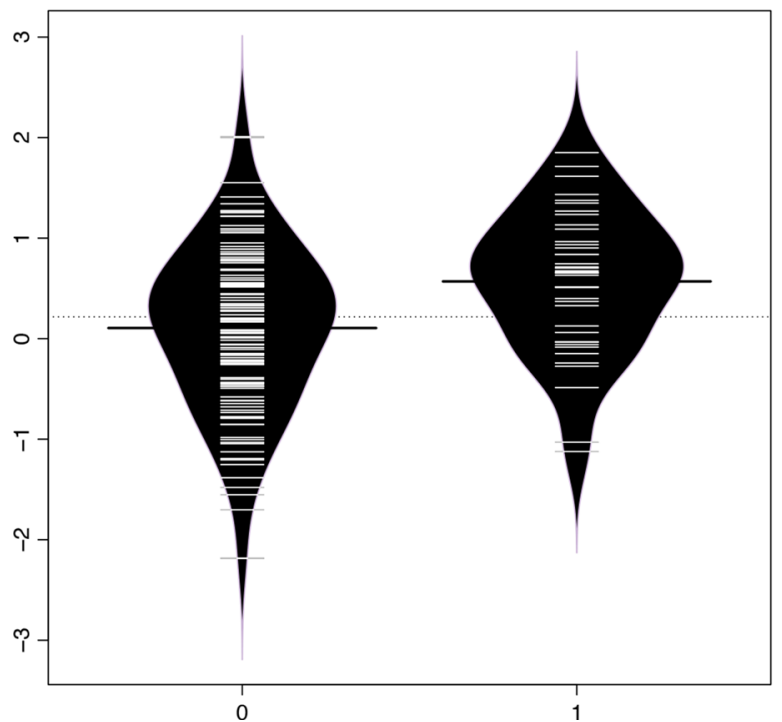

Fig. 2 The relationship between whether alien species recorded for sale in pet shops in our survey $(n=167)$ were introduced into the wild in Taiwan (1) or not (0), and a log sale price, $\mathbf{b} \log$ number of birds for sale, $\mathbf{c}$ song attractiveness and d log body mass. The white lines indicate individual observations, the solid black line represents the mean of the

recorded in Chi's survey were established in univariate analysis (Table $4 \mathrm{~b}$ ). Phylogenetic logistic regression analysis identified four models with $\triangle \mathrm{AICc}<4$ (Table 6). Body mass was again the best predictor of establishment success. The most likely model, with an (b) Estimate: $0.5(0.46,0.54)$; p: $<0.001(<0.001,<0.001)$

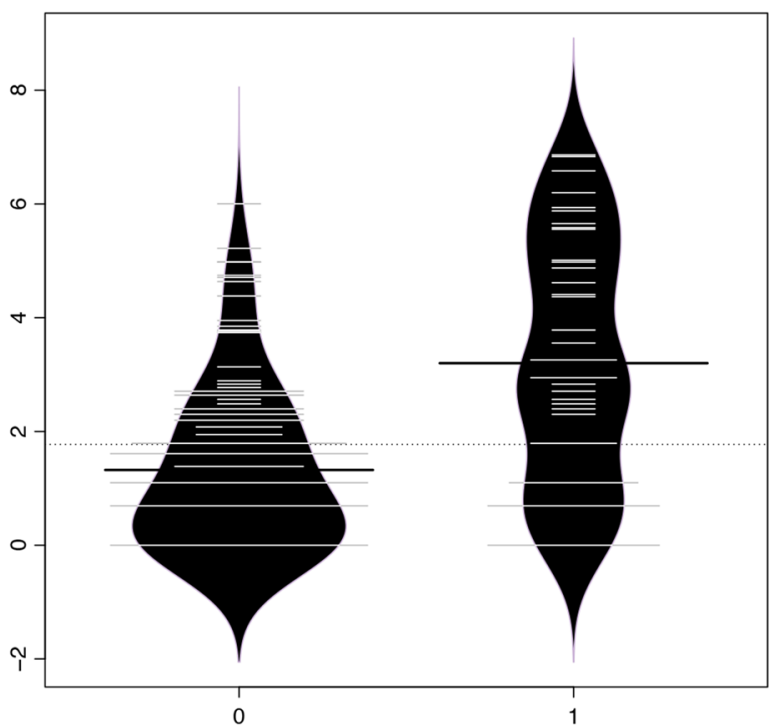

(d) Estimate: $-0.23(-0.4,0.004)$; p: $0.59(0.36,0.91)$

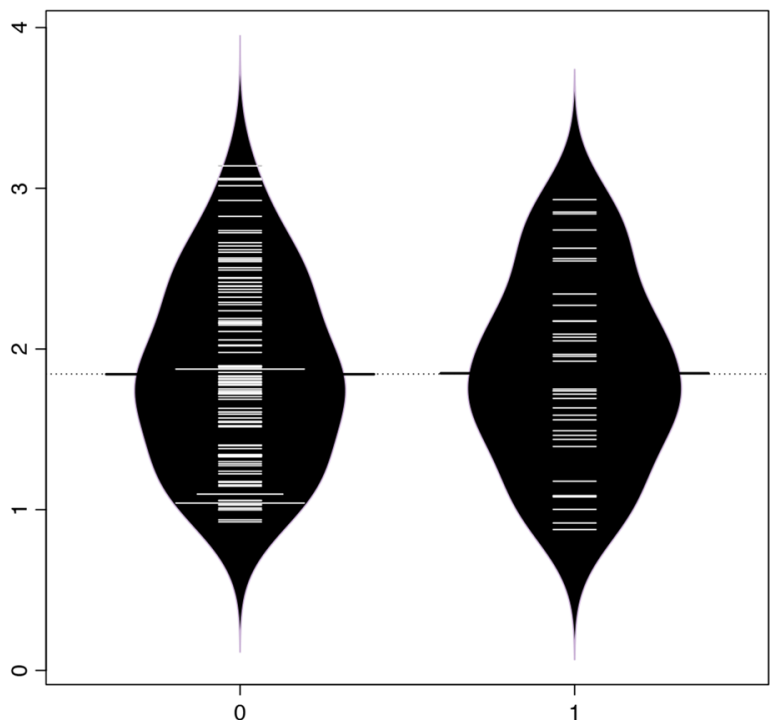

observations, the dotted line represent overall average and the black areas the distribution. Estimates and $p$ values represent: median value of phylogenetic regression coefficients (1st and 99th percentiles), calculated over 100 phylogenetic generalized linear models, each using a different likely phylogeny for the 167 species

Akaike weight of 0.39 , included just body mass, and body mass had a median importance value of 0.89 (1st and 99th percentiles: $0.75,0.95$ ) across all models. Latitudinal mid-point was not included in any of the most likely models. 
Table 2 The results of phylogenetic generalized linear models testing whether alien species recorded for sale in pet shops in our survey were introduced $(\mathrm{n}=167)$

\begin{tabular}{llccc}
\hline Variable & M1 & M2 & M3 & Importance \\
\hline Log numbers of birds for sale & $0.53(0.48,0.54)$ & $0.51(0.5,0.53)$ & $0.46(0.35,0.53)$ & $0.99(0.99,0.99)$ \\
Song attractiveness & $1.08(0.98,1.12)$ & $1.07(1.03,1.1)$ & $0.99(0.83,1.18)$ & $0.99(0.99,0.99)$ \\
Log body mass & & $-0.16(-0.23,-0.09)$ & & $0.29(0.24,0.33)$ \\
Log price & $-2.7(-2.79,-2.43)$ & $-2.34(-2.46,-2.19)$ & $-1.39(-2.96,-0.97)$ & $0.15(0.02,0.24)$ \\
Intercept & $0(0,0)$ & $1.73(1.43,1.96)$ & $1.9(3.32,8.51)$ & $0.11(0.009,0.2)$ \\
$\Delta$ AIC & $0.59(0.49-0.69)$ & $0.24(0.21,0.28)$ & $-0.17,0.04)$ & \\
Akaike weight & & & $0.12)$ \\
\hline
\end{tabular}

M1-M3 are the most likely three models (those with $\triangle \mathrm{AICc}<4$ ). The numbers for each variable represent the median, 1st and 99th percentiles of the model coefficients

\section{Discussion}

The pet trade is one of the primary pathways by which bird species continue to be globally transported (Westphal et al. 2008; McLardy and Burnett 2012). Although it is not the primary aim of the pet trade to introduce birds to new wild environments, pet bird species can become alien invaders if they are released or escape from captivity, and subsequently go on to establish a viable population (Hulme et al. 2008). The situation in Taiwan, where the pet trade is extremely active, suggests that this can easily happen. More than 300 alien bird species have been recorded in the bird trade in Taiwan in just three surveys, and 90 alien bird species have been recorded in the wild. At least 25 alien bird species breed in Taiwan, and 23 of these species have been recorded for sale in Taiwanese pet shops. Thus, the wildlife pet trade appears to be a major driver of the introduction and establishment of alien birds in Taiwan.

Previous studies have shown that the level of international trade and the volume of merchandise imports are positively correlated with the numbers of invasive species across countries (Westphal et al. 2008). This implies that one of the key determinants of the likelihood that a species is introduced is its availability for release or escape (Lee and Shieh 2005; Severinghaus 2007; Blackburn et al. 2015) and therefore species abundance in captivity is predicted to provide important information for understanding the invasion process. Our analysis revealed that, as expected, species abundance in captivity is a strong and consistent predictor of which pet shop species have been recorded at large in the wild. This result also holds for species abundance in captivity as recorded in Chi's survey, two decades earlier, and has also been shown by Lee and Shieh (2005) to apply to estrildid finches for sale in Taiwan.

Species that have been available in the pet market for a long period are also much more likely to find their way into the wild, again reflecting the influence of availability on introduction success. As species recorded in all three surveys were much more likely to have been recorded in the wild (32\%) than those not $(6 \%)$. However, what is more surprising is that 28 of the 90 species recorded in the wild were not recorded for sale in Taiwanese pet shops by any of the three surveys, even though these surveys recorded 312 species for sale in total. This suggests either that species are making their way into the wild from other sources, or perhaps more likely, that there are many more species traded in pet shops than have been identified by the three surveys.

The influence of the availability of species for sale on occurrence in the wild is exacerbated in eastern countries like Taiwan by prayer animal release. This is a common practice in Eastern religions such as Buddhism and Taoism, whereby animals are bought only to be released into the wild for good karma (Severinghaus and Chi 1999). Prayer animal release is extremely active in Taiwan, where it has been estimated that 200 million animals are released annually (Environment and Animal Society of Taiwan 2009). Indeed, in 2014, a religious TV channel in Taiwan (Life TV) launched the aim of having 1000 international animal release events, to be carried out in 
(a) Estimate: $0.34(0.32,0.38)$; P: $0.003(0.001,0.005)$

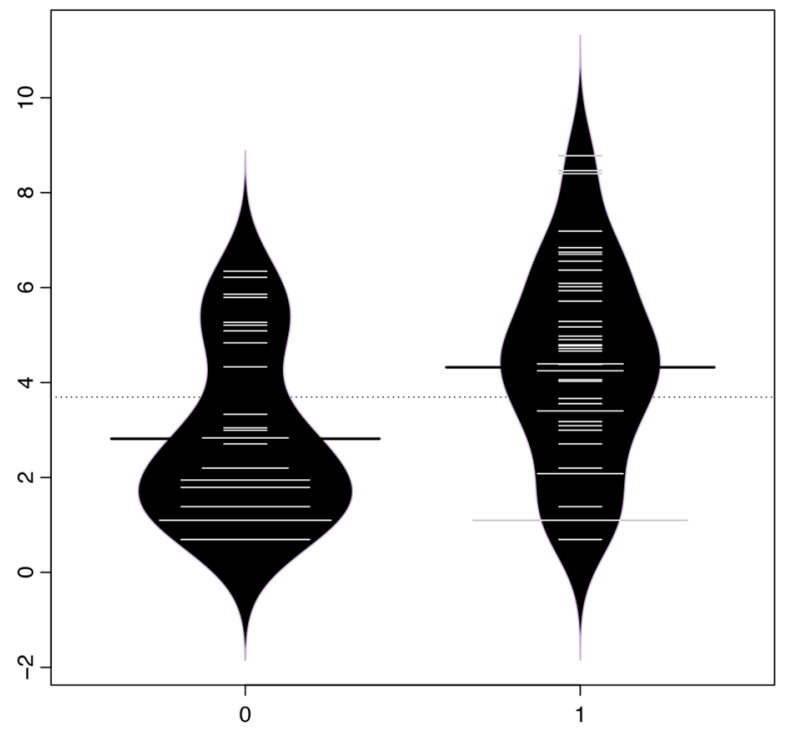

(c) Estimate: $-0.15(-0.28,-0.53)$; P: $0.64(0.28,0.89)$

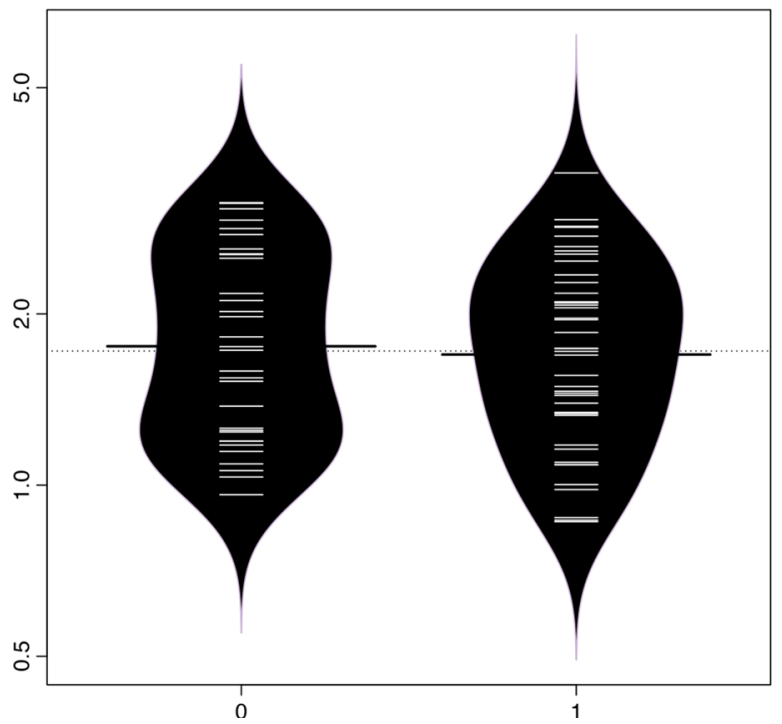

Fig. 3 The relationship between whether alien species recorded for sale in pet shops in Chi's survey $(n=79)$ were introduced into the wild in Taiwan (1) or not (0), and a log number of birds for sale, $\mathbf{b}$ song attractiveness and $\mathbf{c} \log$ body mass. The white lines indicate individual observations, the black line the mean of the observations, the dotted line represent

the shortest possible time. These events were practiced across China, Hong Kong, Thailand, Singapore and Malaysia, but mainly in Taiwan (Hai-Tao 2014). Prayer release often involves large numbers of alien species (Severinghaus and Chi 1999), providing a clear link from trade to wild. (b) Estimate: $0.49(0.43,0.58)$; P: $0.07(0.04,0.11)$

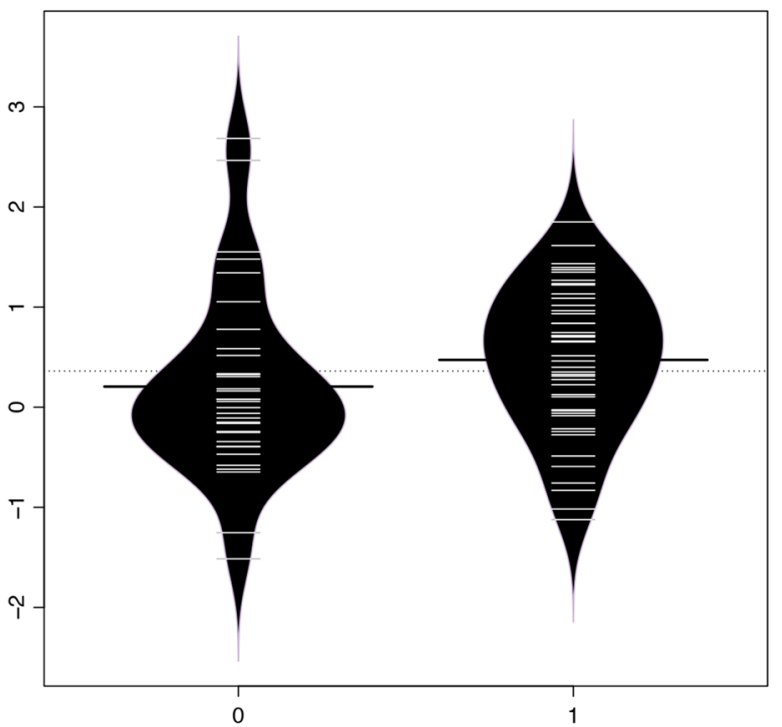

overall average and the black areas the distribution. Estimates and $p$ values represent median value of phylogenetic regression coefficient, (1st and 99th percentiles) calculated over 100 phylogenetic generalized linear models, each using a different likely phylogeny for the 79 species)

Interestingly, while propagule pressure is the most consistent predictor of establishment success in birds (Blackburn et al. 2009a), and other organisms (Lockwood et al. 2005; Hayes and Barry 2008), we did not find strong evidence of an effect of numbers for sale on establishment success for birds in Taiwan (Tables 5, 


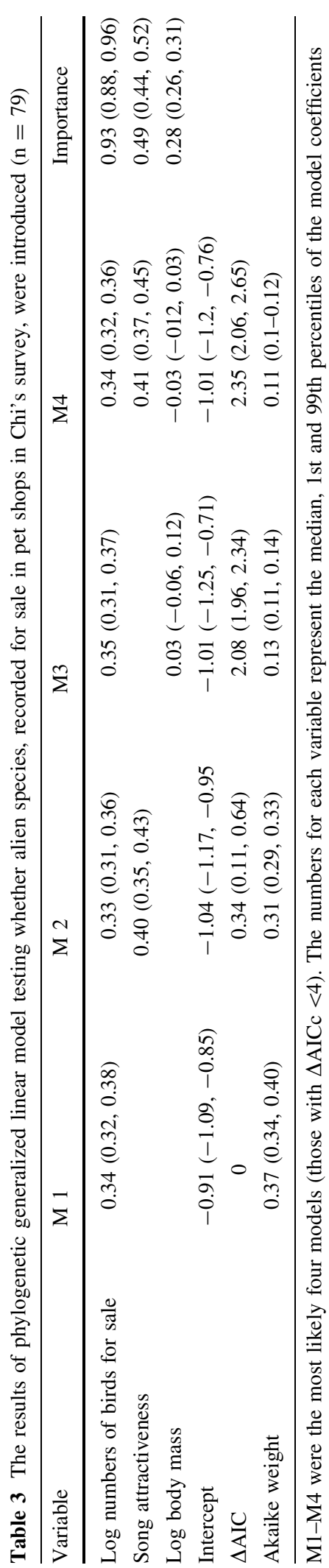

6). We do not have direct information on the numbers of bird released in Taiwan, but the positive effect of numbers for sale on introduction probability (Tables 2, 3) implies that species most commonly sold in Taiwan are more likely to escape or to be released; we would also therefore expect numbers for sale to predict establishment success. One possible reason for this finding is the origin of birds for sale. Carrete and Tella (2008) suggested that whether alien individuals are captive-bred or wild-caught is a key determinant of establishment success, with the latter more likely to establish viable populations. Differences in the origins of different species may affect the likelihood that escaped individuals would establish. Although we do not have direct information on species origin for all the species identified or sale, some established species, such as mynas and starlings, are mainly sourced from the wild. Species claimed to be captive-bred may be in fact wild-caught birds, as Taiwan is one of the main destinations of re-exported species through "wildbird laundering" by other Asian countries (Shepherd et al. 2012). Robust information on the sources of birds in trade would be useful to disentangle these effects.

The number of birds for sale is negatively correlated to price, while cheaper bird species are more likely to be purchased in abundance for release in religious events (Su et al. 2015), and we did find some suggestion of a negative effect of price on establishment success (Table 4). Nevertheless, this effect was weak and inconsistent (Tables 5, 6). The lack of an effect of numbers on establishment success might reflect the poor condition of prayer release birds. These birds have high mortality before they are released. The released birds further suffer $1 \%$ mortality, and up to $35 \%$ of birds with bad condition that can only perform short flights, in the period immediately after release (Hsu 2008; Environment and Animal Society of Taiwan 2009).

Based on our survey, introduced species are likely to have more attractive songs (Table 2 and Figs. 2, 3). Our prediction was that species with higher song attractiveness would be more valuable to their owners, and hence would be better secured from escaping. However, the univariate relationship between introduction success and song attractiveness is not a simple consequence of co-linearity with price, as this relationship is also recovered in multivariate models. In fact, Su et al. (2015) showed a negative correlation 
Table 4 The results of univariate phylogenetic generalized linear model testing whether alien species recorded in the wild were also breeding in the wild, based on species recorded for sale in (a) our survey, $\mathrm{n}=40$; and (b) species recorded in Chi's survey, $\mathrm{n}=46$

\begin{tabular}{lcc}
\hline Variable & Estimate & $p$ \\
\hline (a) & $-0.4(-0.42,-0.38)$ & $0.05(0.04,0.05)$ \\
Log price & $0.1(0.07,0.14)$ & $0.47(0.31,0.6)$ \\
Log numbers of birds for sale & $-0.84(-0.88,-0.72)$ & $0.07(0.06,0.14)$ \\
Latitudinal mid-point (quadratic) & $3.78(3.31,4.04)$ & $0.09(0.06,0.16)$ \\
Latitudinal mid-point $(\log +1)$ & $1.13(1.09,1.17)$ & $0.14(0.13,0.15)$ \\
Log body mass & $0.32(0.23,0.33)$ & $0.06(0.06,0.22)$ \\
Log geographic range & $0.01(-0.08,0.17)$ & $0.93(0.6,0.99)$ \\
(b) & $-0.03(-0.29,0.09)$ & $0.86(0.24,0.99)$ \\
Log numbers of birds for sale & $0.25(-0.15,1.18)$ & $0.18(-0.11,1.13)$ \\
Latitudinal mid-point (quadratic) & $1.05(0.96,1.6)$ & $0.1(0.04,0.12)$ \\
Latitudinal mid-point (log +1$)$ & $0.07(0.59,0.08)$ & $0.62(0.58,0.7)$ \\
Log body mass & & \\
Log geographic range & & \\
\hline
\end{tabular}

Table 5 The results of phylogenetic generalized linear models testing whether alien species recorded in the wild were also recorded breeding there, based on data from alien species recorded as for sale in pet shops in our survey $(n=40)$

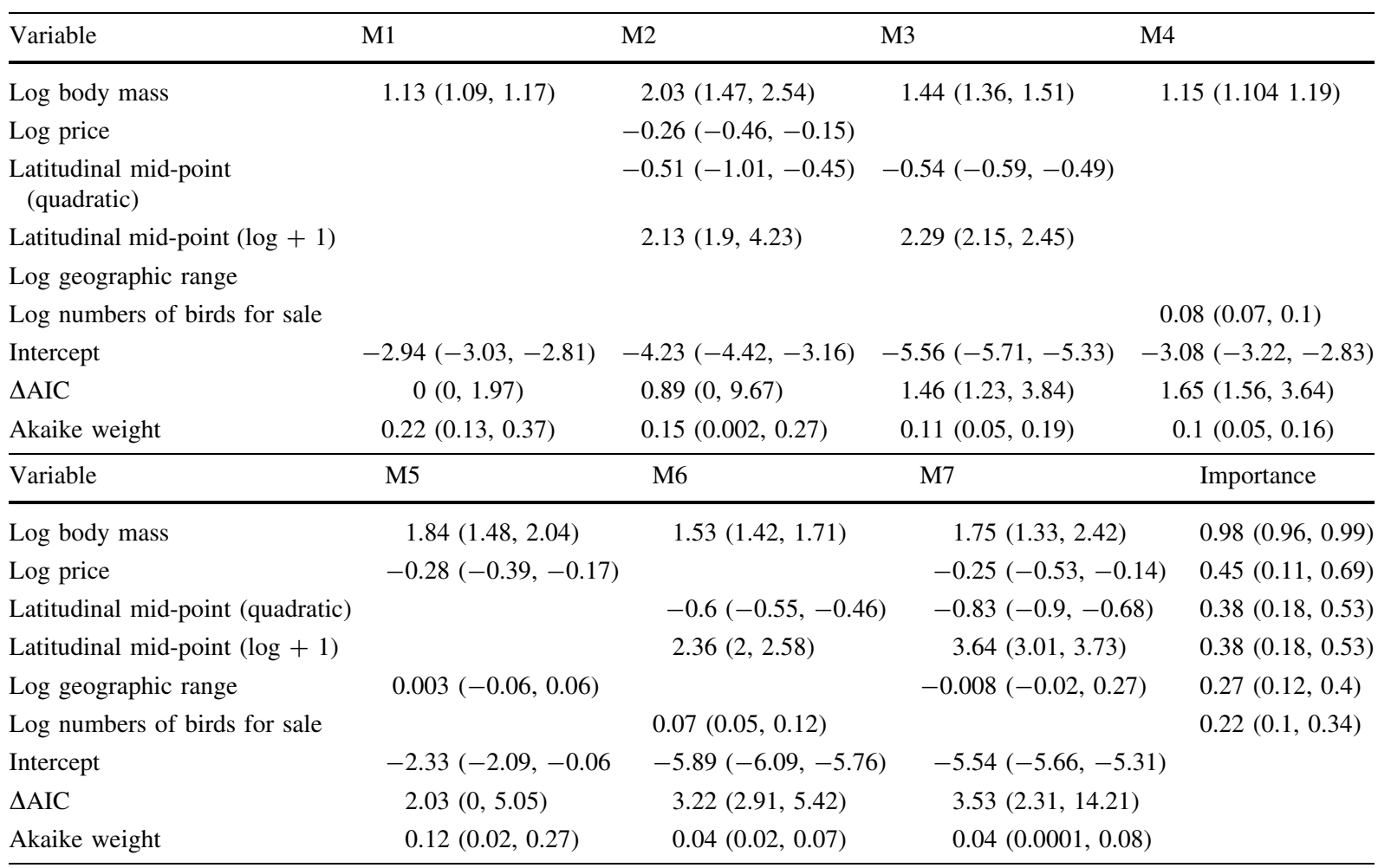

M1-M7 are the most likely seven models (those with $\Delta \mathrm{AICc}<4)$. The numbers for each variable represent the median $(1 \mathrm{st}$ and 99 th percentiles) of the model coefficients

between song attractiveness and a species' price for sale in pet shops. One possibility is that the result is a consequence of the popular cultural activity of bird singing competitions in Taiwan. Bird owners often bring their "best singer" individuals to competitions, which are mostly held outdoors, thereby increasing the 
Table 6 The results of phylogenetic generalized linear model testing whether alien species recorded in the wild were also recorded breeding there, based on data from alien species recorded as for sale in pet shops in Chi's survey $(\mathrm{n}=46)$

\begin{tabular}{|c|c|c|c|c|c|}
\hline Variable & M 1 & M2 & M3 & M4 & Importance \\
\hline $\begin{array}{l}\text { Log body } \\
\text { mass }\end{array}$ & $1.05(0.96,1.6)$ & $1.05(0.88,1.6)$ & $1.68(1.01,1.81)$ & $1.35(0.82,1.8)$ & $0.89(0.75,0.95)$ \\
\hline $\begin{array}{l}\text { Log numbers } \\
\text { of birds for } \\
\text { sale }\end{array}$ & & $0.07(0.03,0.12)$ & $0.15(009,0.2)$ & & $0.37(0.22,0.52)$ \\
\hline $\begin{array}{l}\text { Log } \\
\text { geographic } \\
\text { range }\end{array}$ & & & $0.02(-0.03,0.14)$ & $0.09(-0.09,0.24)$ & $0.28(0.18,0.47)$ \\
\hline Intercept & $-2.46(-3.97,-2.17)$ & $-2.67(-4.5,-2.25)$ & $-5.01(-5.18,-4.09)$ & $-4.59(-4.72,-2.08)$ & \\
\hline$\Delta \mathrm{AIC}$ & $0(0,0.33)$ & $1.15(0,3.05)$ & $3.01(1.31,6.43)$ & $3.07(0,11.18)$ & \\
\hline $\begin{array}{l}\text { Akaike } \\
\text { weight }\end{array}$ & $0.39(0.26,0.56)$ & $0.18(0.1,0.32)$ & $0.09(0.02,0.17)$ & $0.07(0.002,0.31)$ & \\
\hline
\end{tabular}

M1-M4 are the most likely four models (those with $\triangle \mathrm{AICc}<4$ ). The numbers for each variable represent the median $($ and 1 st and 99th percentiles) of the model coefficients

chance that such species might escape into the wild. We found that in some circumstances, songbirds can also be released deliberately by owners, for example, if purchased birds do not sing as well as expected. This would potentially increase the likelihood that such species would be released, and thus observed in the wild, producing the positive relationship between introduction probability and song attractiveness that we observed.

Our analyses revealed no influence of body mass on introduction success in Taiwan. However, it is the most consistent predictor of which introduced species are subsequently recorded as breeding in the wild; this is true for analyses based on data both from our survey and Chi's survey (Tables 5, 6). Some studies have suggested that species with faster population growth are more likely to succeed in establishing, because such populations can rapidly escape the dangers of small population size (Moulton and Pimm 1986; Cassey 2002). In contrast, other studies have suggested that these species are likely to fail in establishment because they face higher stochastic demographic variance than those with lower growth rate (Sæther et al. 2004; Blackburn et al. 2009a). Comparative studies of the relationship between establishment success and life history also suggest that species with slower population growth rates are more likely to succeed in establishing (Blackburn et al. 2009b). Species with slow population growth rate tend to have longer life-span, low rates of reproduction and larger body mass (Blackburn et al. 2009a), and may also be species that prioritise future over current reproduction (Sol et al. 2012). Our finding of a positive relationship between body mass and establishment success supports the latter view: features associated with slow population growth rates are more likely to determine whether or not introduced species succeed in establishing in Taiwan, following introduction. Such species may be more likely to establish because they are less susceptible to the negative effects of demographic and environmental stochasticity on small founding populations (Sæther et al. 2004; Blackburn et al. 2009a).

Our analyses are potentially affected by the difficulty of determining, for many alien species, whether individuals recorded in the wild derive from captivity or have occurred naturally as vagrants. There are 127 species identified as vagrants in the checklist of the birds of Taiwan (Ding et al. 2012), which is more than the numbers of alien species recorded in the wild since 1980 in our data. It is possible that some of the individuals of these species originated in captivity, or vice versa, that some of the species recorded as alien introductions are actually vagrants. We took the conservative line that all individuals of species that (Ding et al. 2012) listed as vagrant in Taiwan were actually vagrants. Therefore, the numbers of alien species recorded in the wild is perhaps likely to be underestimated. Vagrants are more likely to come from regions in geographic proximity to Taiwan, but 
we do not think that this would alter our conclusions. For example, our survey showed that species from nearby geographic regions tend to be sold in larger numbers in pet shops, while species sold in larger numbers are more likely to be introduced (Table 2). Therefore, excluding vagrants that are actually aliens is likely to exclude species more abundant in shops, and hence bias our results away from the results we found.

In conclusion, our analyses combining records on alien bird species found in the wild in Taiwan with surveys of the pet bird trade spanning 20 years reveal that introduction success is dependent primarily on a species availability for release or escape. This is likely to be because species sold in large numbers are also liberated in large numbers, especially as a result of the practice of prayer animal release. However, this does not translate into an effect of numbers on establishment success, perhaps because many of those birds released are in poor condition. Rather, establishment success is greater for species that theory suggests will be less susceptible to the negative effects of demographic and environmental stochasticity on small founding populations. Thus, the pet trade influences bird invasions in Taiwan by determining which species are exposed to novel environments, but which of those introduced species goes on to establish may depend more on their intrinsic life histories (Sol et al. 2012; Cassey et al. 2014).

Acknowledgments We thank William Chi and Bao-Sen Shieh for supplying pet shops surveys, the Chinese Wild Bird Federation for the database and Endemic Species Research Institute for supplying data from their Breeding Bird Taiwan project. This study received financial support from Institute of Zoology, Zoological Society of London.

Open Access This article is distributed under the terms of the Creative Commons Attribution 4.0 International License (http:// creativecommons.org/licenses/by/4.0/), which permits unrestricted use, distribution, and reproduction in any medium, provided you give appropriate credit to the original author(s) and the source, provide a link to the Creative Commons license, and indicate if changes were made.

\section{References}

BirdLife International (2008) Nearly half of all bird species are used directly by people. In: Presented as part of the
BirdLife State of the world's birds website. http://www. birdlife.org/datazone/sowb/casestudy/98

Blackburn TM, Cassey P (2007) Patterns of non-randomness in the exotic avifauna of Florida. Divers Distrib 13:519-526

Blackburn TM, Duncan RP (2001) Determinants of establishment success in introduced birds. Nature 414:195-197. doi: $10.1038 / 35102557$

Blackburn TM, Cassey P, Duncan RP et al (2004) Avian extinction and mammalian introductions on Oceanic Islands. Science 305:1955-1958. doi:10.1126/science.1101617

Blackburn TM, Cassey P, Lockwood JL (2009a) The role of species traits in the establishment success of exotic birds. Glob Change Biol 15:2852-2860. doi:10.1111/j.13652486.2008.01841.x

Blackburn TM, Lockwood JL, Cassey P (2009) Avian invasions: the ecology and evolution of exotic birds. http:// public.eblib.com/EBLPublic/PublicView.do?ptiID= 679349. Accessed 10 Jul 2012

Blackburn TM, Pyšek P, Bacher S et al (2011) A proposed unified framework for biological invasions. Trends Ecol Evol 26:333-339. doi:10.1016/j.tree.2011.03.023

Blackburn TM, Su S, Cassey P (2014) A Potential metric of the attractiveness of bird song to humans. Ethology 120: 305-312. doi:10.1111/eth.12211

Blackburn TM, Lockwood JL, Cassey P (2015) The influence of numbers on invasion success. Mol Ecol. doi:10.1111/mec. 13075

Carrete M, Tella J (2008) Wild-bird trade and exotic invasions: a new link of conservation concern? Front Ecol Environ 6:207-211. doi:10.1890/070075

Carrete M, Edelaar P, Blas J et al (2012) Don't neglect preestablishment individual selection in deliberate introductions. Trends Ecol Evol 27:67-68. doi:10.1016/j.tree.2011. 11.011

Cassey P (2002) Life history and ecology influences establishment success of introduced land birds. Biol J Linn Soc 76:465-480. doi:10.1046/j.1095-8312.2002.00086.x

Cassey P (2008) Are there body size implications for the success of globally introduced land birds? Ecography 24:413-420. doi:10.1111/j.1600-0587.2001.tb00476.x

Cassey P, Prowse TAA, Blackburn TM (2014) A population model for predicting the successful establishment of introduced bird species. Oecologia 175:417-428. doi:10. 1007/s00442-014-2902-1

Chen H, Boutros PC (2011) VennDiagram: a package for the generation of highly-customizable Venn and Euler diagrams in R. BMC Bioinform 12:35. doi:10.1186/14712105-12-35

Cheng J-Z (2010) Monitoring distribution and breeding situation of the specific alien birds in Taiwan. In: Forestry Bureau, Council of Agriculture Executive Yuan, Forestry Bureau, Council of Agriculture Executive Yuan. Taiwan

Chi WL (1995) An investigation report on pet bird trade in Taiwan. Green Consumer's Foundation, Taipei, Taiwan

Core Team R (2014) R: a language and environment for statistical computing. Austria, Vienna

Davis MA (2009) Invasion biology. Oxford University Press, Oxford

Ding T-S, Juan C-S, Lin R-S, et al (2012) The 2012 CWBF Checklist of the Birds of Taiwan. Bird Record Committee, Chinese Wild Bird Federation, Taiwan 
Duncan RP, Blackburn TM, Cassey P (2006) Factors affecting the release, establishment and spread of introduced birds in New Zealand. In: Allen RB, Lee WG (eds) Biological invasions in New Zealand. Springer, Dordrecht, pp 137-154

Dunning JB (1992) CRC handbook of avian body masses. CRC Press, Boca Raton

Environment and Animal Society of Taiwan (2009) The investigation of prayer animal releases in Taiwan. Environment and Animal Society of Taiwan and Human Society International, Taiwan

Frenot Y, Chown SL, Whinam J et al (2005) Biological invasions in the Antarctic: extent, impacts and implications. Biol Rev 80:45-72. doi:10.1017/S1464793104006542

Fritz SA, Purvis A (2010) Selectivity in mammalian extinction risk and threat types: a new measure of phylogenetic signal strength in binary traits: selectivity in extinction risk. Conserv Biol 24:1042-1051. doi:10.1111/j.1523-1739.2010.01455.x

García-Moreno J, Clay RP, Ríos-Muñoz CA (2007) The importance of birds for conservation in the Neotropical region. J Ornithol 148:321-326. doi:10.1007/s10336-0070194-5

Gaston KJ (1991) How large is a species' geographic range? Wiley Behalf Nord Soc Oikos 61:434-438

Gaston KJ (1994) Measuring geographic range sizes. Wiley Behalf Nord Soc Oikos 17:198-205

Green RE (1997) The influence of numbers released on the outcome of attempts to introduce exotic bird species to New Zealand. J Anim Ecol 66:25. doi:10.2307/5961

Hai-Tao (2014) A thousand of international prayer animal releases. In: Hai-Tao Mercy Work. http://www.lifetv.org. tw/2012/index.htm

Hayes KR, Barry SC (2008) Are there any consistent predictors of invasion success? Biol Invasions 10:483-506. doi:10. 1007/s10530-007-9146-5

Ho LST, Ane C (2014) A linear-time algorithm for Gaussian and Non-Gaussian trait evolution models. Syst Biol 63:397-408. doi:10.1093/sysbio/syu005

Hsu F-H (2008) Is prayer birds release a good karma? In: A monograph of the invasive species in Taiwan. Taiwan Environmental Information Association, TEIA, Taipei City

Hulme PE, Bacher S, Kenis M et al (2008) Grasping at the routes of biological invasions: a framework for integrating pathways into policy. J Appl Ecol 45:403-414

Ives AR, Garland T (2010) Phylogenetic logistic regression for binary dependent variables. Syst Biol 59:9-26. doi:10. 1093/sysbio/syp074

Jetz W, Thomas GH, Joy JB et al (2012) The global diversity of birds in space and time. Nature 491:444-448. doi:10.1038/ nature 11631

Kampstra P (2008) Beanplot: a boxplot alternative for visual comparison of distributions. J Stat Softw Code Snippets 28:1-9

Ko CJ, Fan MW, Jiang YX et al (2013) 2012 Taiwan breeding bird survey annual report. In: Council of Agriculture, Endemic Species Research Institute, Nantou, Taiwan

Kolar CS, Lodge DM (2001) Progress in invasion biology: predicting invaders. Trends Ecol Evol 16:199-204

Lee TW, Shieh BS (2005) Pet sales of exotic estrildid birds in relation to the field-records in Taiwan. Endem Species Res $7: 1-12$
Lockwood JL, Cassey P, Blackburn T (2005) The role of propagule pressure in explaining species invasions. Trends Ecol Evol 20:223-228. doi:10.1016/j.tree.2005.02.004

McLardy C, Burnett N (2012) A review of the trade in live wild birds into the European Union 1994-2003-orders Psittaciformes. Falconiformes and Strigiformes, JNCC report

Moulton M, Pimm S (1986) Species introductions to Hawaii. In: Mooney HA, Drake JA (eds) Ecology of biological invasions of North America and Hawaii. Springer, New York, pp 231-249

Nash SV (1993) Sold for a song: the trade in Southeast Asian non-CITES birds. Traffic International, Cambridge

Olson DM, Dinerstein E, Wikramanayake ED et al (2001) Terrestrial ecoregions of the world: a new map of life on earth. Bioscience 51:933-938

Olson VA, Davies RG, Orme CDL et al (2009) Global biogeography and ecology of body size in birds. Ecol Lett 12:249-259. doi:10.1111/j.1461-0248.2009.01281.x

Orme CDL, Davies RG, Olson VA et al (2006) Global patterns of geographic range size in birds. PLoS Biol 4:e208

Orme D, Freckleton R, Thomas G et al (2013) Caper: comparative analyses of phylogenetics and evolution in $\mathrm{R}$. $\mathrm{R}$ package version 0.5.2. http://CRAN.R-project.org/package=caper

Richardson DM, Pyšek P, Carlton JT (2010) A compendium of essential concepts and terminology in invasion ecology. In: Richardson DM (ed) Fifty years of invasion ecology. Wiley, Oxford, pp 409-420

Runde DE, Pitt WC, Foster JT (2007) Population ecology and some potential impacts of emerging populations of exotic parrots. In: Manag Vertebr Invasive Species, pp 338-360

Sæther B, Engen S, Pape Møller A et al (2004) Life-history variation predicts the effects of demographic stochasticity on avian population dynamics. Am Nat 164:793-802. doi: $10.1086 / 425371$

Severinghaus LL (1999) Exotic birds in Taiwan. Wild Birds 7:45-58

Severinghaus LL (2007) The breeding ecology and dispersal of Taiwan and light-vented bulbuls in Kenting National Park. J Natl Park 17:27-41

Severinghaus LL, Chi L (1999) Prayer animal release in Taiwan. Biol Conserv 89:301-304

Shepherd CR, Stengel CJ, Nijman V (2012) The export and reexport of CITES-listed birds from the Solomon Islands. TRAFFIC, Southeast Asia, Petaling Jaya, Selangor, Malaysia

Shieh B, Lin Y, Lee T et al (2006) Pet trade as sources of introduced bird species in Taiwan. Taiwania 51:81-86

Shiu H, Stokes L (2008) Buddhist animal release practices: historic, environmental, public health and economic concerns. Contemp Buddh 9:181-196. doi:10.1080/ 14639940802556529

Sibley CG, Monroe BL (1990) Distribution and taxonomy of the birds of the world. Yale University Press, New Haven

Sol D, Maspons J, Vall-llosera M et al (2012) Unraveling the life history of successful invaders. Science 337:580-583. doi: $10.1126 /$ science. 1221523

Su S, Cassey P, Blackburn TM (2014) Patterns of non-randomness in the composition and characteristics of the Taiwanese bird trade. Biol Invasions. doi:10.1007/s10530014-0686-1 
Su S, Cassey P, Vall-llosera M, Blackburn TM (2015) Going cheap: determinants of bird price in the Taiwanese pet market. PLoS One 10:e0127482. doi:10.1371/journal. pone. 0127482

Westphal MI, Browne M, MacKinnon K, Noble I (2008) The link between international trade and the global distribution of invasive alien species. Biol Invasions 10:391-398. doi:10.1007/s10530-007-9138-5
Wilson JRU, Dormontt EE, Prentis PJ et al (2009) Something in the way you move: dispersal pathways affect invasion success. Trends Ecol Evol 24:136-144. doi:10.1016/j.tree. 2008.10.007

Wong J-J, Wu Y-C, Tang P-C (2012) The management and trade status of parrots in Taiwan. Council of Agriculture, Executive Yuan, Taiwan 